\title{
Review of combine harvester losses for maize and influencing factors
}

\author{
Keru Wang, Ruizhi Xie, Bo Ming, Peng Hou, Jun Xue, Shaokun Li* \\ (Institute of Crop Sciences, Chinese Academy of Agricultural Sciences, Key Laboratory of Crop Physiology and Ecology, \\ Ministry of Agriculture and Rural Affairs, Beijing 100081, China)
}

\begin{abstract}
The high harvest losses associated with the mechanical harvesting of maize in China are currently a major barrier to the adoption of this technology. This paper summarizes works of literature regarding harvest losses from the combine harvesting of maize in China and abroad. The main findings are as follows: (1) In 2012-2019, 2987 samples data obtained from the major maize production areas of China showed that the average harvest loss was $345.2 \mathrm{~kg} / \mathrm{hm}^{2}(3.5 \%$ of the average yield), with losses ranging from 0 to $9288.5 \mathrm{~kg} / \mathrm{hm}^{2}$; (2) The harvest losses from combine harvesting are mainly caused by the dropping of ears. The ear losses include the pre-harvest loss caused by ear abscission, damage caused by maize borer, lodging, and the ear loss during combine harvesting, and the main pre-harvest loss is caused by lodging; (3) Harvest losses are affected by maize variety, planting mode, cultivation management, pests and diseases, weather conditions during harvesting, harvest date, combine harvester type, harvester adjustment, operator proficiency, and the terrain conditions of the maize field; (4) The harvest losses from combine harvesting are also related to the type of header, feeding and threshing methods, the adjustment of header stripping clearance, feeding amount, forward speed, cylinder or rotor speed, and the clearance between the cylinder and the concave of the harvester. However, the combine losses mainly come from header losses. In order to reduce the harvest losses, the following solutions were proposed: (1) Breed and select maize varieties which are resistant to lodging, especially during the field drying of mature grains, as well as those resistant to maize borer and stalk rot; (2) Select varieties suitable for grain harvest - which requires matching the accumulated-temperature demand of the maize hybrids, optimal plant density, row spacing, and irrigation and fertilizer management with the light and heat conditions of the production area while cultivating uniform populations and healthy plants - as well as preventing and controlling damage from maize borer, stalk rot, and ear rot, harvesting at the appropriate time; (3) Develop and select advanced maize combine harvesters, formulate standardized operating procedures for harvesting machinery, and standardize field operation; (4) select appropriate agricultural machinery and agronomic practices, and improve the training of maize producers and harvester operators.
\end{abstract}

Keywords: maize, grain, combine harvest, ear dropping, kernel dropping, harvest loss, influence factors DOI: $10.25165 /$ j.ijabe.20211401.6034

Citation: Wang K R, Xie R Z, Ming B, Hou P, Xue J, Li S K. Review of combine harvester losses for maize and influencing factors. Int J Agric \& Biol Eng, 2021; 14(1): 1-10.

\section{Introduction}

The mechanical harvesting of maize grain involves using a combine harvester to simultaneously perform the operations of ear picking, threshing, and cleaning on mature maize plants in the field ${ }^{[1,2]}$. The high harvest losses which are associated with the combine harvesting of maize is one of the main barriers to the promotion of maize mechanical grain harvesting technology in China $^{[3-5]}$. In the 1970 s, mechanical harvesting technology began to be widely used for the harvesting of maize grain in Europe and North America ${ }^{[6]}$. Much research had been carried out on the components of harvest $\operatorname{loss}^{[7,8]}$, the causes of harvest loss ${ }^{[9-16]}$, and

\section{Received date: 2020-07-23 Accepted date: 2020-10-29}

Biographies: Keru Wang, $\mathrm{PhD}$, Professor, research interest: theory and technology of maize mechanization production, Email: wangkeru@caas.cn; Ruizhi Xie, $\mathrm{PhD}$, Professor, research interest: maize physiology and ecology, Email: xieruizhi@caas.cn; Bo Ming, PhD, Associate Professor, research interest: efficient utilization of environmental resources in crop production systems, Email: mingbo@caas.cn; Peng Hou, PhD, Associate Professor, research interest: physiology and ecology of maize high yield cultivation, Email: houpeng@caas.cn; Jun Xue, PhD, research interest: maize lodging resistance. Email: xuejun5519@126.com.

*Corresponding author: Shaokun Li, PhD, Professor, research interest: physiology and ecology of maize high yield and high efficiency cultivation. Institute of Crop Sciences, Chinese Academy of Agricultural Sciences, No. 12 Zhongguanchun, South Street, Haidian District, Beijing 100081, China. Tel: +86-10-82108891, Email: lishaokun@caas.cn. measures to reduce harvest $\operatorname{loss}^{[17-25]}$, thus providing technical support for the continuous improvement of maize varieties and the continuous improvement of the performance of harvesting machines. Consequently, maize grain harvesting technology has matured. However, compared to Europe and North America, the development of maize grain mechanical harvesting technology in China is at a relatively early stage, and at present, combine harvesting is used on less than $10 \%$ of the country's maize cultivation area. Due to a lack of research on the harvest loss from combine harvesting, the application and promotion of this technology have been seriously restricted. To address this issue, this paper summarizes data regarding the harvest loss from the combine harvesting of maize and its influencing factors in China and abroad and analyzes the main causes of this harvest loss. Furthermore, based on this, the measures and strategies for reducing harvest loss during the combine harvesting of maize were put forward.

\section{Mechanical harvest loss and standard of mechanical harvest loss rate}

Mechanical harvest loss during the combine harvesting of maize is a common problem in maize production both in China and other countries. Sumner and Williams ${ }^{[26]}$ reported that the average harvest loss rate of mechanically harvested maize grain is generally $2 \%-4 \%$ of the total crop yield. According to research by Gleim et al. ${ }^{[14]}$ from Ohio State University, under normal harvest 
conditions, the ear loss from combine harvesting should not exceed $1 \%$ of the total crop yield, the cylinder loss should not exceed $0.3 \%$ of the total yield, and the separator kernel loss should not exceed $0.5 \%$ of the total yield, that is, the total harvest loss rate should not exceed $1.8 \%$ of the total yield. Additionally, Paulsen et al. ${ }^{[27]}$ found that, in Brazil, the total harvest loss from the combine harvesting of maize was $0.3 \%-3.6 \%$ of the total crop yield. Furthermore, in 2012-2015, our team obtained 1698 sample data for combine harvested maize from 186 field plots in 15 major maize-producing provinces or cities in China; statistical analysis showed that the average harvest loss was $247.5 \mathrm{~kg} / \mathrm{hm}^{2}$ (4.1\% of the average yield). A large difference was observed among plots, with losses ranging from $1.0 \mathrm{~kg} / \mathrm{hm}^{2}$ to $4198.5 \mathrm{~kg} / \mathrm{hm}^{2}$, and the coefficient of variation was $164.5 \%{ }^{[28]}$. Moreover, Guo et al. ${ }^{[29]}$ investigated the loss rates of different maize harvesting methods in China, such as manual harvesting, mechanical ear harvesting, and mechanical grain harvesting. The results showed that the loss rate of mechanical grain harvesting was the highest, followed by mechanical ear harvesting, and manual harvesting had the lowest loss rate. Mechanical ear harvesting was investigated in Minle County, Gansu Province; the average harvest loss rate in 2016 was $4.8 \%$ of the yield, the loss rate from threshing was $3.4 \%$ of the yield, and the total loss rate was $8.2 \%$ of the yield. Mechanical grain harvesting was investigated in Heilongjiang Province; the harvest loss rate ranged from $10.0 \%$ to $15.5 \%$ of the yield and the average loss rate was $12.4 \%$ of the yield. Manual harvesting was investigated in Gongzhuling County, Jilin Province; the average harvest loss rate ranged from $1.0 \%$ to $2.3 \%$ of the yield. The standard of maize harvest loss in the United States is no more than $3 \%$ of the yield ${ }^{[30]}$, and the same standard is applied in countries such as Brazil and Argentina. The Brazilian Ministry of Agriculture recommends that the harvest loss for the combine harvesting of maize should not exceed $60 \mathrm{~kg} / \mathrm{hm}^{2[27]}$. Meanwhile, China's national standard, "Technical Conditions for Maize Harvesting Machinery" (GBT-21962-2008) ${ }^{[31]}$, stipulates that the harvest loss rate from the mechanical harvesting of maize should be $\leq 5 \%$ of the yield.

\section{Sources and measurement methods of mechanical harvest loss}

\subsection{Classification of harvest loss}

The harvest loss during the combine harvesting of maize can be divided into two types. One is the loss caused by the dropping of ears and kernels before harvesting caused by planting and management factors-for example, the ear and grain dropping caused by stalks and panicles being drilled and eaten by maize borer and the ear dropping caused by stalk lodging; this loss is referred to as pre-harvest loss and is not caused by the operation of harvesting machinery. The second type is the loss from falling ears and kernels, which is also known as the harvest loss ${ }^{[7]}$. Ayres et al. ${ }^{[8]}$ classified the harvest loss into visible loss and invisible loss according to whether the fallen grains and ears can be observed in the field after mechanical grain harvesting: the visible loss refers to the ears and kernels that are dropped in the field after the harvester completes the harvesting operation, while the invisible loss refers to the materials that are broken into fragments and powder during the process of threshing, including the imperfect kernels that are not shelled from the top of the cobs during the threshing process. This material is blown out and scattered in the field during separation and cleaning, and the amount of invisible loss is closely related to the grain moisture content and grain broken rate ${ }^{[8]}$. The visible loss caused by the operation of harvesting machinery can be divided into header loss (gathering loss), cylinder loss, separation loss, and cleaning loss (or shoe loss) ${ }^{[8]}$. Header loss is mainly caused by snapping roll ear losses in the process of splitting plants, pulling stalks, picking ears, and gathering and transferring ears; these losses are mainly caused by the dropping of ears, but also caused by falling grains, especially when the grain moisture content is low. After the ears enter the threshing cylinder of the combine harvester, processing losses are caused during the processes of threshing, separation, and cleaning; these losses include combine cylinder losses (caused by imperfect shelling action, which causes some kernels to remain on the cob as they pass through the machine; this loss amounts to $0.1 \%-0.2 \%$ of the yield), separation loss (caused by the grain becoming attached to fragments of stems, leaves, or husks which then pass over the sieves and out of the combine; this loss accounts for $0.3 \%-3.0 \%$ of the yield), and cleaning losses and losses due to the presence of grain in the chaff fraction (accounting for $0.1 \%-0.5 \%$ of the yield). Threshing losses are mainly caused by incomplete threshing and the breakage of grains, while separation losses and cleaning losses are mainly caused by incomplete separation and improper cleaning, respectively, which results in the loss of grains wrapped and entrained by non-grain material such as fragments of cob and husks. Therefore, maize grain yield should be calculated as the sum of harvester yield, visible loss, and invisible $\operatorname{loss}^{[32]}$. Reducing harvest loss is one of the most important ways to increase maize grain yield.

Paulsen et al. ${ }^{[33]}$ investigated maize harvest losses in Brazil and found that the grain yield of maize ranged from 6937 to 11044 $\mathrm{kg} / \mathrm{hm}^{2}$, the pre-harvest ear loss ranged from 0 to $42 \mathrm{~kg} / \mathrm{hm}^{2}$, and the total harvest loss ranged from 36.2 to $320.6 \mathrm{~kg} / \mathrm{hm}^{2}$; among these losses, the ear loss at header accounted for the largest proportion of the total harvest loss and ranged from 0 to $237 \mathrm{~kg} / \mathrm{hm}^{2}$. Additionally, according to the statistical analysis of 2987 sets of grain harvest quality samples obtained between 2012 and 2019, the average kernel loss in the 15 major maize-producing provinces and cities of China was $113.6 \mathrm{~kg} / \mathrm{hm}^{2}$, accounting for $23.5 \%$ of the total loss, and the average ear loss was $351.2 \mathrm{~kg} / \mathrm{hm}^{2}$, accounting for $76.5 \%$ of the total loss. Therefore, it is considered that falling ear loss is the main contributor to harvest losses ${ }^{[34]}$.

\subsection{Measurement method of harvest loss for the combine} harvesting of maize

The main maize-producing states in the United States have their own methods to measure the harvest loss from the mechanical harvesting of maize, however, these methods are generally similar. The measurement method of the state of Missouri is now described as an example $e^{[35]}$ and is also described graphically in Figure 1. Losses are determined by counting the number of full-size ears (weight approximately $340 \mathrm{~g}$ ) or the equivalent weight in smaller ears found in an area of $40.47 \mathrm{~m}^{2}$; each full-size ear represents about 1 bushel per $62.7 \mathrm{~kg} / \mathrm{hm}^{2}$ of loss. The number of kernels per $0.9290 \mathrm{~m}^{2}$ is counted to determine kernel losses; 2 kernels per $0.0929 \mathrm{~m}^{2}$ equals $62.7 \mathrm{~kg} / \mathrm{hm}^{2}$ of loss. The row length in meter per $40.5 \mathrm{~m}^{2}$ should be determined according to the row width. The width of the sample area is determined according to the header width of the harvester, generally according to the cutting width, and the length of the sample area is determined according to the cutting width based on an area of $40.47 \mathrm{~m}^{2}$ or $0.9290 \mathrm{~m}^{2}$. The following steps are followed for the investigation of fallen ears and grains: First, the combine is stopped at a location where the crop is representative of the entire field. In the first step, the total ear loss 
and total kernel loss from the combine harvesting are determined. The header is then shut off. The harvester is then back off for a distance equal to its length and is then shut off. Then, the area $\left(40.47 \mathrm{~m}^{2}\right)$ for the measurement of ear loss and the area $\left(0.929 \mathrm{~m}^{2}\right)$ for the measurement of kernel loss are delimited respectively in the harvested area. Then, the lost ears and kernels within the determined sample areas are measured and subsequently used to calculate the total ear loss and kernel loss, respectively.

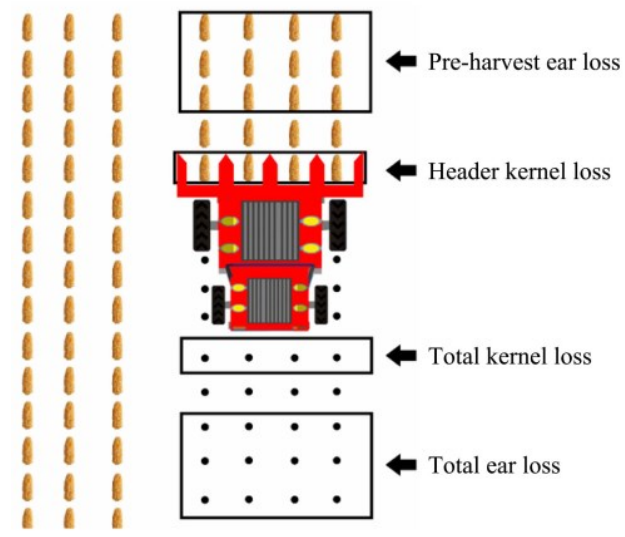

Figure 1 Sketch of the measurement method of maize harvest loss in the state of Missouri, United States ${ }^{[35]}$

The second step is to determine the pre-harvest numbers of dropped ears and fallen kernels. In front of the combine harvester, two sample areas are delimited as in the first step (i.e., an area of $40.47 \mathrm{~m}^{2}$ for ear loss and an area of $0.929 \mathrm{~m}^{2}$ for kernel loss), and the numbers of fallen ears (which includes the ears of lodged plants) and fallen kernels in these two areas are measured, respectively. These values are then taken as the pre-harvest ear loss and kernel loss.

The third step is to determine the ear loss and kernel loss caused by the combine harvesting of maize. These are calculated by subtracting the pre-harvest ear or kernel loss from the total ear or kernel loss. The kernel loss caused by the harvester includes the loss caused by the header, threshing, separation, and cleaning; this includes the loss of kernels attached to cobs (this part belongs to the combine threshing loss), which is caused by incomplete threshing.

In order to further understand the composition of the combine harvest losses, a rectangle frame is constructed using a plastic clothesline and four-wire pegs to obtain a frame with an area of $0.929 \mathrm{~m}^{2}$. The width of the frame should be equal to the width of the crop rows. The frame is then placed over each row behind the machine, and the number of loose kernels on the ground within the frame is counted. This number is taken as the total loose kernel loss (header loss plus separating loss). Before moving the frame to the next row behind the machine, the number of kernels that are still attached to the threshed cobs is counted, ignoring small kernels at the butt or tip end of the cob. This number represents cylinder loss. Then, the frame is placed over each harvested row in front of the harvester where the separator has not yet passed, and the loose kernels within the frame are counted; this value represents the header kernel loss. For each row, the header loss is subtracted from the header loss plus separating loss, and the resulting value represents the separation kernel loss.

In the measurement method of maize harvest loss from combine harvesting recommended by the Brazilian Ministry of Agriculture $^{[27]}$, the investigation area for kernel loss is $2 \mathrm{~m}^{2}$ in one header width and the investigation area for ear loss is $30 \mathrm{~m}^{2}$ in one header width.

At present, the measurement method for maize harvest loss adopted in China involves randomly selecting sample points in the harvested plot. The sampling area is $2 \mathrm{~m}$ in length and a header in width. All of the fallen ears and kernels in the sample area are gathered, and then the total weight of the fallen ears and kernels is measured, respectively. Based on the grain moisture content at harvest, the grain weight of the fallen ears and kernels per unit area is adjusted to $14 \%$ moisture content. The measurement of each treatment (i.e., each test of a variety) is repeated three times. Then, the yield data of the harvested field are used to calculate the ear loss rate, kernel loss rate, and total loss rate.

Additionally, aside from the losses mentioned above, there exists a "hidden loss" due to maize grains that are broken and pulverized by threshing, which cannot be picked up and are therefore not accounted for in the calculated kernel loss. This hidden loss will be higher when the grain breakage rate is relatively high. Future research should investigate potential methods to measure this hidden loss.

\section{Effects of variety, cultivation management, and harvest date on maize harvest losses from combine harvesting}

\subsection{Effects of maize variety on mechanical harvest losses}

Mahoney et al. ${ }^{[2]}$ used early-maturing (short-season), full-season, and late-maturing maize varieties to study the effects of delayed maize harvest in southern Ontario, Canada. The results showed that, with the delay of harvest time, the harvest loss of all varieties increased; however, the harvest loss increased more in early-maturing varieties, mainly due to the fact that the connection strength between ears and stalks and the stalk standing ability decreased faster in early-maturing varieties after delayed harvest, which led to the increase of ear dropping and lodging during mechanical harvesting and thus increased the harvest loss. Many studies have shown that the difference in harvest loss among maize varieties is mainly related to the degree of grain maturity at harvesting and the lodging resistance of plants standing in the field ${ }^{[17,24,36]}$. Lodging tends to increase the loss of mechanical harvesting. The risk of lodging can be reduced by breeding and selecting lodging-resistant varieties. A study from Ohio State University found that, if the harvest is delayed, late-maturing maize hybrids had less lodging and higher yield than early-maturing hybrids with a similar stem strength ${ }^{[17]}$. Additionally, Klenke et al. ${ }^{[17]}$ used BS9 (CB) C4 breeding materials to develop four types of test varieties to study the effects of maize variety on the mechanical harvest loss of maize in Iowa. These test varieties included (1) varieties susceptible to the first and second generations of European maize borer (ECB), (2) varieties resistant to the first generation and susceptible to the second generation of ECB, (3) varieties resistant to the first and second generations of $\mathrm{ECB}$, and (4) varieties susceptible to the first generation and resistant to the second generation of ECB. It was found that the varieties with a strong connection between ear and stem, and the varieties resistant to the second generation of ECB at the later stage of maize growth, had significantly lower maize harvest losses. These findings suggest that the harvest loss is closely related to the resistance to the maize borer, stalk rot, and lodging in the later growth stage, as well as to the tendency for ear dropping.

4.2 Effects of planting density and row spacing on harvest loss

Maize is typically planted in rows, and mechanical harvesting 
requires the maize header to align accurately with the row. Therefore, the row spacing has an impact on harvest loss. Hanna $^{[15]}$ used a CASE IH 1620 axial-flow grain combine harvester to harvest maize with different row spacings in order to determine whether visible machine harvest losses differed between narrow and wide maize heads and the extent of visible machine harvest loss when $38 \mathrm{~cm}$ rows were harvested by a maize head with a row width of $76 \mathrm{~cm}$. The research showed that when the row spacing and maize head were matched, machine losses were generally similar between the conventional $76 \mathrm{~cm}$ maize head and the single gathering chain $38 \mathrm{~cm}$ maize head, although losses were slightly lower than the conventional maize head. Machine ear drop losses were found to be excessive when a $76 \mathrm{~cm}$ maize head was used, even at a slow travel speed of $3.2 \mathrm{~km} / \mathrm{h}$, when harvesting maize planted in $38 \mathrm{~cm}$ rows late in the season. Over $90 \%$ of machine losses occurred at the maize head rather than in the threshing, separating, and cleaning areas. Additionally, Zhang et al. ${ }^{[19]}$ carried out mechanical ear-harvesting experiments on summer maize with row spacings of $50 \mathrm{~cm}, 60 \mathrm{~cm}$, and $70 \mathrm{~cm}$, respectively, using a header with a row spacing of $60 \mathrm{~cm}$. The results showed that the harvest loss rates were $12.2 \%, 7.5 \%$, and $7.9 \%$ of the yield for row spacings of $50 \mathrm{~cm}, 60 \mathrm{~cm}$, and $70 \mathrm{~cm}$, respectively. The authors concluded that the matching of planting row spacing and harvester header row spacing could reduce harvest loss and recommended that a planting row spacing of $60 \mathrm{~cm}$ is most suitable for machine harvesting in the Huang-Huai-Hai summer maize region of China. The above research shows that the harvest loss of maize planted with a narrow row spacing is higher than that of maize planted with a wide row spacing, which may be related to the fact that a wide row spacing is easier to accurately align with the header in mechanical harvesting. Therefore, by using GPS or Beidou navigation technology to achieve accurate row alignment for sowing and harvesting, the impact of different planting row spacings on the harvest loss can be significantly reduced if the harvester maize head row spacing is matched to the planting row spacing.

Furthermore, since there is a significant positive correlation between lodging rate and harvest loss rate, planting density has a significant impact on harvest loss due to the high lodging rate under high planting density ${ }^{[9,17,18,22]}$. Reducing planting density can improve the stalk quality and standability and reduce the lodging rate, and can thus reduce the harvest loss ${ }^{[22]}$.

4.3 Effects of the management of irrigation, fertilization, diseases, insects, and weeds on harvest loss

Reasonable irrigation and fertilization can increase the strength of maize stalk and thus reduce the ear drop loss during harvest. Additionally, due to sufficient grain filling, uniform ear size, and effective grain threshing after ripening, the ear drop loss of the maize header and threshing loss will be reduced by reasonable irrigation and fertilization ${ }^{[13,37]}$. According to some studies, under dry farming systems, the maize harvest loss is low in years with abundant rainfall in the growing season, while the harvest loss is higher in years with high temperature and drought stress due to the early senescence of maize plants ${ }^{[13]}$. On the other hand, regarding disease and insect damage, maize borer and stalk rots are the main diseases and insect pests that cause maize lodging and ear dropping. In the United States, the European maize borer can cause yield loss at harvest by promoting plant lodging and ear dropping before harvest, and the loss can increase significantly with increasing harvest delay. Klenke et al. ${ }^{[17]}$ found that the second generation of European maize borer can significantly increase harvest losses in the mechanical harvesting of maize in Iowa since this generation coincides with the stage of ear growth and development after silking and its larvae mainly harm the maize ears, drilling and mothing the stalk under the ear, resulting in the increase of ear falling and stem bending and lodging during mechanical harvesting. However, control measures against the second generation of maize borer can significantly reduce harvest losses. The pathogen which causes maize stalk rot produces an enzyme that degrades cell walls by decomposing cellulose in the cell wall ${ }^{[38]}$; meanwhile, spores rapidly germinate into mycelium and enter the cells of the epidermis, cortex, and vascular bundle tissue on the stalk surface, causing the stalk tissue to lose water, shrink, hollow, soften, and even rot, thus leading to stalking breakage ${ }^{[39-41]}$. Stalk rot can also cause ears to become smaller, uneven ear size, and premature senescence, resulting in an increase of ear dropping and grain dropping during mechanical harvesting ${ }^{[42]}$. Additionally, maize plants with stalk rot often have incomplete ear development, insufficient grain filling, and high grain hardness, which leads to higher cylinder loss during harvest ${ }^{[42]}$. Mahoney et al. ${ }^{[22]}$ studied the effects of delayed maize harvest, applying four treatments (VT to R2) before and after tasseling and either spraying fungicide (azoxystrobin+propiconazole) or not spraying. The results showed that the treatments with fungicide spraying significantly reduced the harvest losses, mainly due to the fact that spraying fungicide can effectively control the occurrence of stalk rot, delay leaf aging, improve stalk quality, and reduce the lodging rate in delayed harvest, and can thus reduce the harvest losses in the combine harvesting of maize. Weeds, including volunteer maize, increase the rate of dropped ears and fallen kernels during the mechanical harvesting of maize ${ }^{[43]}$. On the one hand, weeds in maize fields can aggravate maize diseases and insect pests and increase competition with maize plants for water, fertilizer, and light, which weakens the maize plants and increases the lodging rate during harvest. On the other hand, weeds also affect the picking, threshing, separation, and cleaning of ears during mechanical harvesting, thus increasing the rate of ear and grain dropping.

4.4 Effects of grain moisture content, harvest time, and meteorological conditions during harvesting on harvest losses

The moisture content of maize grains is related to the harvest time and the characteristics of mechanical threshing and affects the cylinder loss during mechanical threshing. Previous studies have found that the harvest loss is smallest when the grain moisture content is between $22 \%$ and $26 \%$. When the grain moisture content is lower than $22 \%$ or higher than $26 \%$, the harvest losses are larger ${ }^{[18]}$. Piggott ${ }^{[20]}$ found that when the moisture content of maize grains is $26 \%-29 \%$, natural kernel dropping accounts for only $1 \%$ of the yield, however when the moisture content drops below $25 \%$, natural kernel dropping rapidly increases to about $10 \%$ of the yield. Nolte et al. ${ }^{[12]}$ and others showed that, in Ohio, when the grain moisture content reaches $26 \%$, the average yield loss increased by $10-40 \mathrm{~kg} / \mathrm{hm}^{2}$ for each day that harvest was delayed. Moreover, Shauck and Smeda ${ }^{[43]}$ showed that, in Missouri, when the grain moisture content decreased from $21 \%-24 \%$ to $16.5 \%$ $20.0 \%$ and $13 \%-16 \%$, the harvest loss increased by $35 \%$ and $52 \%$, respectively. Furthermore, according to an investigation by the Monsanto Company ${ }^{[44]}$, when the grain moisture content is $23 \%-25 \%$, the harvest loss is $1 \%-2 \%$ of the yield, and when the grain moisture content is $17 \%-19 \%$, the harvest loss increases to $2 \%-8 \%$ of the yield. Additionally, Brandon ${ }^{[45]}$ showed that, in Mississippi, the average harvest loss was $1 \%-3 \%$ of the yield when 
the grain moisture content was $26 \%$, but the harvest loss increased to $10 \%-15 \%$ of the yield when the grain moisture content was $15 \%$. After maize physiological maturity, during the ear dry-down of maize plants standing in the field, the attachment strength of ears to the stalk and that of kernels to the cob will decrease with decreasing grain moisture content, resulting in the increase of ear dropping and kernel falling before and during harvest ${ }^{[46]}$. Moreover, some studies have shown that when the grain moisture content is lower than $20 \%$ the ears begin to fall off from the stalk and that this ear dropping increases with further grain drying ${ }^{[47]}$. Allen et al. ${ }^{[13]}$ showed that, when maize was harvested at a grain moisture content of $15 \%$, the lodging rate and the harvest loss were higher by $42 \%$ and $30 \%$, respectively, compared with harvesting at a grain moisture content of $25 \%$. Li et al. ${ }^{[2]}$ investigated maize grain harvest by combine in the Huang-Huai-Hai summer maize region, and showed that with decreasing grain moisture content the kernel loss during mechanical grain harvesting first decreased and then increased, with the lowest kernel loss occurring at a grain moisture content of $20.4 \%$. Additionally, Li et al. ${ }^{[2]}$ also found that the ear loss during harvesting increased with decreasing grain moisture content and that when the grain moisture content was lower than $16.5 \%$, the ear loss was more than $5 \%$ of the yield.

The harvest loss of maize varies for different harvest periods due to the different grain moisture content, the different health states of plants, and different degrees of stalk lodging ${ }^{[48]}$. Field investigations by the United States Department of Agriculture (USDA) ${ }^{[49]}$ in the states of Illinois, Indiana, Iowa, and Nebraska found that the harvest loss rate of maize harvested in October was $5 \%$ of the yield, but that the harvest loss rate increased to $18 \%$ of the yield for maize harvested in December. Additionally, the same study found that, in Ohio, beyond 15 October, the lodging rate increased by $5 \%$ for each week of harvest delay, and $1 / 3$ of the lodging would become the harvest loss ${ }^{[12]}$. Furthermore, in 2000 and 2001, harvested maize at $14 \mathrm{~d}, 28 \mathrm{~d}, 42 \mathrm{~d}, 56 \mathrm{~d}$, and $70 \mathrm{~d}$ after physiological maturity, and found that while there was no significant difference in the yield between different harvest times in 2000 , the yield of the harvest at $70 \mathrm{~d}$ was $15 \%$ lower than that at 14 $\mathrm{d}$ in $200^{[50]}$. Moreover, data collected by the American Society of Agricultural and Biological Engineers (ASABE) in 2006 showed that when maize harvesting was started at a grain moisture content of $22 \%$, the yield of maize decreased by $0.3 \% / \mathrm{d}$ of harvest delay ${ }^{[51]}$. Ayres et al. ${ }^{[8]}$ proposed that the expansion of maize planting area leads to a longer harvest period, which is suggested to be one of the reasons for the increase of ear dropping during harvesting. Additionally, it has been reported that in parts of Argentina the harvest loss is as high as $627.7 \mathrm{~kg} / \mathrm{hm}^{2}$, which is mainly related to the loss caused by untimely harvest and high lodging rate; when maize was harvested by the combine, the grain moisture content was typically $22 \%$, however, contents could reach $29 \%{ }^{[52]}$. Lodging is the most important cause of ear loss ${ }^{[23]}$. In 1966, Byg et al. ${ }^{[10]}$ investigated the harvest dropping ear loss before and after rainfall and snowfall on November 2 in Ohio State, and their results also supported the view that the increase of lodging caused by rainfall and snowfall increases the harvest loss. Before 2 November, the ear loss ranged from 0 to $376.2 \mathrm{~kg} / \mathrm{hm}^{2}$ and the average ear loss was $112.86 \mathrm{~kg} / \mathrm{hm}^{2}$, while the kernel loss ranged from 18.81 to $532.95 \mathrm{~kg} / \mathrm{hm}^{2}$ and the average kernel loss was $175.56 \mathrm{~kg} / \mathrm{hm}^{2}$; meanwhile, after 2 November, the ear loss ranged from 25.08 to $438.9 \mathrm{~kg} / \mathrm{hm}^{2}$ and the kernel loss ranged from 6.27 to $1059.63 \mathrm{~kg} / \mathrm{hm}^{2}$, with an average kernel loss of $445.17 \mathrm{~kg} / \mathrm{hm}^{2}$. It is considered that the increase of harvest loss is mainly related to the increase in dropping ear loss caused by lodging. Xue et al. ${ }^{[33]}$ found that, in China, the yield loss in mechanical grain harvesting caused by lodging was mainly due to the loss from dropping ears. Additionally, for each $1 \%$ increase in lodging rate, the ear loss was found to increase by $0.1 \%$ and $0.2 \%$ of the yield in a spring maize area and a summer maize area, respectively. Parvej et al. ${ }^{[37]}$ studied maize harvesting by combine in Iowa, and found that within a harvest window of one month, the number of ears within $30 \mathrm{~cm}$ of the ground increased by $7 \%$, and these ears were considered to represent the ear loss that could not be gathered by the combine header. From the above, it can be seen that the effect of harvest time on harvest loss is mainly due to the change of dropping ear rate and lodging rate at different harvest times. The later the harvest time is, the lower the grain moisture content and the higher the dropping ear loss and falling kernel loss at harvest time. Additionally, the meteorological conditions during the harvesting period have a certain influence on the mechanical harvesting loss of maize. A study in Ohio found that almost $90 \%$ of harvest loss was related to the delaying of the harvest to the middle of November and that the difference in harvest loss among different years was related to the weather conditions at harvest time ${ }^{[8]}$. Furthermore, Gleim et al. ${ }^{[14]}$ investigated 55 maize combine harvesters in Ohio and found that the total visible harvest loss in the field accounted for only $1 \%$ of the estimated yield when the harvesters were operated under good weather conditions meeting the harvesting requirements; however, when the weather conditions were bad (e.g., wind and snow), the harvest loss increased significantly. Moreover, a survey in Wisconsin showed that when maize harvest is delayed to the next spring rather than being conducted in autumn if the intervening winter experiences heavy snow, the harvest yield is $37 \%$ lower than that if the crop were harvested in the previous autumn; meanwhile, if there is little snow in the winter, the harvest yield is only $10 \%$ lower than that in autumn ${ }^{[54]}$. Shauck et al. ${ }^{[43]}$ found that, in Missouri, there were significant differences in harvest loss between different years: In the same year, the harvest loss was lower in October and November and higher in September and December. The differences were related to different weather conditions during harvest, especially rainfall and temperature. The difference in harvest loss among different regions is also mainly related to differences in weather conditions during the harvest period ${ }^{[48]}$. For example, the harvest loss of maize in central Iowa is 2.6 times higher than that in Missouri, mainly since these two regions have significantly different climates during harvest time ${ }^{[21]}$.

\section{Effects of combine type, adjustment, and operation on harvest loss}

\subsection{Effects of maize header type and feeding mode on harvest loss}

Shauck ${ }^{[43]}$ compared the maize harvesting performance of 30 combine harvesters in Missouri and found that the header loss was $34 \%$ lower with headers with an automatic adjustment balance function than with headers without this function; the header loss was $46 \%$ lower with a header with an eight-row width than with a header with a 6-row width, and the lowest header loss was achieved with a 12-row header, which was the widest header investigated. Additionally, for the same type of header, the loss rate of newly purchased headers was found to be lower than that of older headers. Furthermore, our team investigated the maize harvest loss of a disturbing header and a header that was specially designed for use 
with maize and found that the harvest loss was significantly higher for the former than for the latter. It was found that the loss rate of the disturbing header was mainly caused by ear drop loss from both sides of the header and that the harvest loss was lower with a wide header than with a narrow header. Moreover, Xue et al. ${ }^{[53]}$ showed that the harvest ear loss rate of a fully fed header increased exponentially with increasing lodging rate while the harvest ear loss rate of a semi-fed header increases linearly with increasing lodging rate. At present, fully fed harvesters are mainly used in North and Northwest China and semi-fed harvesters are mainly used in the Huang-Huai-Hai summer maize area. Under the same lodging rate, the ear drop rate is higher for semi-fed harvesters than for fully fed harvesters.

\subsection{Effects of different threshing methods on harvest loss}

The design of novel threshing and separating device that offers improved production efficiency and reduced grain loss is the main development trend for modern maize combine harvesters. According to the different principles of maize ear threshing, harvesters can be divided into two types: rasp bar cylinder and axial-flow cage-type sheller. Axial-flow harvesters can be divided into three types according to the ear feeding mode, namely cutting-flow type, axial-flow type, and a combination of these two types. According to the placement mode, threshing cylinders can be divided into longitudinal axial-flow threshing cylinders and horizontal axial-flow threshing cylinders; the longitudinal axial-flow type includes single axial-flow devices and double axial-flow devices. It has generally been observed that harvesters with longitudinal axial-flow have a longer threshing process and a lower loss rate and crushing rate ${ }^{[25]}$. In Illinois, Paulsen et al. ${ }^{[55]}$ harvested maize with three different moisture contents on 16 September, 26 September, and 12 October, respectively, using three types of harvesters, namely a traditional harvester, a single axial-flow harvester and a double axial-flow harvester. The results showed that the harvest loss varied greatly between the different harvesters $\left(2.1-73.6 \mathrm{~kg} / \mathrm{hm}^{2}\right)$, however, the difference was not significant. Shauck and Smeda ${ }^{[43]}$ compared harvesters equipped with a rotary threshing device and a conventional threshing device, respectively, and found that the harvesters equipped with the former had a lower harvest loss; however, again, the difference was not significant. Additionally, for the threshing device with tangential (horizontal) axial-flow, increasing the rotation speed of the cylinder improved the threshing ability. With the increasing tangential speed of the cylinder, the threshing loss decreased, however, the grain broken rate increased. Rademacher and Bingen ${ }^{[56]}$ found that when the ear enters the cylinder such that its cob is parallel to the axis of the cylinder, the ear can pass through the threshing device at twice the speed that it entered the device in a tangential direction; the front clearance between the cylinder and concave should be $10 \mathrm{~mm}$ less than the average diameter of the ear and the back clearance should be equal to the average diameter of the ear cob so that the setting loss rate and breakage rate are low. From the above, it can be seen that the axial-flow threshing separation structure with a single or double cylinder can greatly improve the threshing efficiency, and accordingly this approach should be applied and developed in the future.

5.3 Effects of stripper plate clearance, feed quantity, forward speed, cylinder rotation speed, and cylinder-concave clearance on the harvest loss

Lien et al. ${ }^{[57]}$ measured the harvest loss of 12 combine harvesters in 13 maize fields on eight farms in the Midwestern United States, namely Indiana, Iowa, Illinois, and Nebraska. The results showed that: (1) The lowest harvest losses were equal to $1.0 \%$ of the yield and the highest harvest losses were equal to $27.5 \%$ of the yield, with the harvest losses of most fields being less than $1.5 \%$ of the yield and the harvest losses being independent of the kernel size; (2) Snapping roll losses were generally greater than other machine losses. Improper stripper plate clearance was responsible for the majority of these losses. The header loss is the most important part of harvest loss; (3) Header ear loss was found to be a function of the forward travel speed, plant density, and stalk lodging rate. When the width of the header exceeded 4 rows, the forward speed was reduced by $0.4 \mathrm{~km} / \mathrm{h}$. Minimum header loss occurred at a forward travel speed of approximately $4.8 \mathrm{~km} / \mathrm{h}$; (4) Cylinder loss was found to be a function of cylinder peripheral speed, the clearance between the cylinder and the concave, and cylinder loading. The separating and cleaning losses were found to be a function of forwarding travel speed, plant density, yield, and feed quantity. Losses were greater when the combine was operated at a speed greater than $4.8 \mathrm{~km} / \mathrm{h}$ at densities of approximately 62000 plants $/ \mathrm{hm}^{2}$. Pishgar-Komleh et al. ${ }^{[58]}$ showed that when the feed quantity was $2.5 \mathrm{~kg} / \mathrm{s}$, the total loss rate was $9.3 \%$, with the loss from harvesting machinery being $8.6 \%$; the highest loss was the threshing loss, accounting for $5.4 \%$. The harvesting forward travel speed had a significant impact on the header ear loss and the cylinder loss in the threshing process, however, it had no significant impact on the separation loss. The cylinder peripheral speed had a significant impact on the threshing loss; however, the forward traveling speed and the cylinder rotational speed had no significant impact on the separation loss. The mechanical loss increased with increasing feed quantity, with the lowest harvesting loss (total loss rate $7.6 \%$ ) being observed at harvesting forward travel speed of $3 \mathrm{~km} / \mathrm{h}$ and a cylinder rotational speed of $400 \mathrm{r} / \mathrm{min}$, and the highest threshing loss rate (7.1\%) being observed at a forward travel speed of $5 \mathrm{~km} / \mathrm{h}$ and a cylinder rotational speed of $600 \mathrm{r} / \mathrm{min}$. Therefore, these results suggest that the forward traveling speed and the cylinder rotational speed have a significant impact on the harvest loss.

Wiersma et al. ${ }^{[30]}$ found that the forward traveling speed of a harvester affects the harvesting loss by affecting the operation of straw walkers. In Brazil, Paulsen et al. ${ }^{[33]}$ found that reducing the harvester forward travel speed can reduce the separation loss of combine harvesting. Furthermore, Gleim et al. ${ }^{[14]}$ investigated 52 maize combine harvesters in Ohio and observed that, under good harvesting conditions, when the harvesting forward traveling speed was $4.5 \mathrm{~km} / \mathrm{h}$, the total visible loss in the field accounted for only $1 \%$ of the estimated yield. Moreover, in another study, at harvesting forward traveling speeds of $2.29-5.20 \mathrm{~km} / \mathrm{h}$, the total harvest losses were found to be between $0.16 \%-27.54 \%$ of the yield $^{[57]}$. It has been shown that the largest harvest loss rate and the largest change in the harvest loss rate are caused by the snapping roll, which ranges from $0.06 \%$ to $11.10 \%{ }^{[57]}$. Additionally, the stripper plate clearance has a great influence on the header loss. When the clearance is set to $2.54 \mathrm{~cm}$, the header loss is only $3.99 \mathrm{~kg} / \mathrm{hm}^{2}$; when it is increased to $2.70 \mathrm{~cm}$, the header loss increases to $11.83 \mathrm{~kg} / \mathrm{hm}^{2}$; and when it is increased to $2.86 \mathrm{~cm}$, the header loss increases to $39.27 \mathrm{~kg} / \mathrm{hm}^{2}$. After the header loss, the next highest loss is the cylinder loss. Cylinder loss is affected by both cylinder rotational speed and the clearance between the cylinder and the concave. The cylinder loss ranges from $0.13 \mathrm{~kg} / \mathrm{hm}^{2}$ (loss rate is less than $1 \%$ of the yield) to $258.7 \mathrm{~kg} / \mathrm{hm}^{2}$ (loss rate is $9.75 \%$ of the yield). The clearance between the cylinder and the concave should be adjusted based on 
the ear diameter and grain size. The losses from separation and cleaning are lower than the losses from the header and threshing and range from $0.008 \%$ to $6.570 \%$. The losses from separation and cleaning are a function of the forward traveling speed, planting density, and yield. In the study of Lien et al. ${ }^{[57]}$, the planting density ranged from 49000 to 57000 plants $/ \mathrm{hm}^{2}$, and the separation and cleaning losses were found to increase rapidly with increasing forward traveling speed when the forward traveling speed exceeded $4.8 \mathrm{~km} / \mathrm{h}$. Hanna ${ }^{[15]}$ compared visible machine losses of a $76 \mathrm{~cm}$ maize head used on $76 \mathrm{~cm}$ and $38 \mathrm{~cm}$ rows with those of a single gathering chain $38 \mathrm{~cm}$ maize head used on $38 \mathrm{~cm}$ rows. They divided the total machine losses into head and threshing/separating losses and investigated three harvesting treatments. The results showed that the highest proportion of harvest loss came from header loss, which accounted for more than $90 \%$ of the total machine loss. Even with a slower forward traveling speed, header loss could not be reduced. The header loss was mainly the loss from falling ears and ranged from $0.9 \mathrm{mg} / \mathrm{hm}^{2}$ to $1.3 \mathrm{Mg} / \mathrm{hm}^{2}$, and the falling kernel loss of threshing at the stalk pulling roller was between $0.5 \%$ and $3.3 \%$. At low feed rates, over $90 \%$ of machine losses occurred at the maize-head rather than in the threshing, separating, and cleaning areas. When the harvesting forward traveling speed was $4.8 \mathrm{~km} / \mathrm{h}$ (normal harvesting speed), the header loss was still found to be the main component of the combine harvest loss, and the losses inside the machine were negligible. Additionally, header loss is related to the increase of ear drop loss caused by late harvest. When harvesting maize with stalk rot, the kernel loss is less than or equal to about $1 \%$ of the yield, however, the ear drop loss caused by the header is very high, accounting for $83 \%-100 \%$ of the total harvest loss.

Srison et al. ${ }^{[59]}$ showed that the grain moisture content significantly affected the breakage of grains and energy consumption during harvesting but did not affect the loss from threshing. With increasing grain moisture content, the breakage rate and energy consumption increased. Feed quantity was found to affect power consumption but was not shown to affect breakage rate or threshing loss. Moreover, it was found that energy consumption increased with increasing feed quantity. Additionally, the rotational speed of the cylinder was observed to have a significant effect on the grain breakage rate, threshing loss, and energy consumption; with increasing rotational speed, the breakage rate and power consumption increased and the threshing loss decreased.

Chuan-Udom and Chinsuwan ${ }^{[60]}$ showed that the threshing loss of an axial thresher was significantly affected by the grain moisture content, the rotation speed of the cylinder, the feeding amount, and the inclination angle of the plant (cob, husk, leaves, stem) and the guide leaf except the grain. When the rotation speed of the cylinder increased, the threshing loss rate decreased, however, the breakage rate increased. Furthermore, it was found that the inclination angle of the vibrating screen affected the loss rate and that the rotation speed of the drum affected the breakage rate but did not impact the loss rate. However, another study of threshing with an axial-flow cylinder showed that when the grain moisture content was in the range of $14 \%-28 \%$ and the feeding amount was in the range of $0.5-2.5 \mathrm{t} / \mathrm{h}^{[61]}$, the grain moisture content and the feeding amount did not affect the threshing loss at a certain drum speed (cylinder peripheral speeds (RS) of 12 280-13 $000 \mathrm{~cm} / \mathrm{s}$ ); however, the rotor speed was found to significantly affect the threshing loss (RS in the range of 8000-12 $000 \mathrm{~cm} / \mathrm{s}$ ).

\subsection{Harvester adjustment affects harvest loss}

Sumner et al. ${ }^{[26]}$ noted that the loss rate in the mechanical harvesting of maize is generally between $2 \%$ and $4 \%$, however, if the condition of the harvester is not checked during harvesting or the stage in the harvesting process where the loss may occur is not known, then loss rates of $10 \%$ or more may occur. A large number of studies have found that excessive header loss is mainly caused by improper clearance adjustment of the ear plucking plate. Monsanto $^{[62]}$ showed that the loss caused by the ear plucking plate was $62.7 \mathrm{~kg} / \mathrm{hm}^{2}$, accounting for $1 / 3$ of the total loss, and the median loss was $37.62 \mathrm{~kg} / \mathrm{hm}^{2}$. When the rotating speed of the cylinder and the clearance between the cylinder and the concave was adjusted properly, there was no serious consequence to the grains being left on the cob without being threshed; the average threshing loss was $31.35 \mathrm{~kg} / \mathrm{hm}^{2}$ and the median was $15.68 \mathrm{~kg} / \mathrm{hm}^{2}$. The highest observed loss was $282.15 \mathrm{~kg} / \mathrm{hm}^{2}$, however, this was caused by a serious imbalance between the rotational speed of the cylinder and the clearance between the cylinder and the concave. SteponaviČius et al. ${ }^{[63]}$ proposed that the correct adjustment of the cylinder rotational speed and the clearance between the cylinder and the concave can reduce the threshing loss to $0.3 \%$ of the yield or lower. Moreover, Pekkevicius et al. ${ }^{[64]}$ tested the threshing of wet maize ears (grain moisture content $>35 \%$ ) in 2003-2005. The results showed that adjusting the rotating speed of the cylinder and the clearance between the cylinder and the concave can effectively reduce the threshing loss. Additionally, the findings suggested that when the rotating speed of the cylinder is $17.3 \mathrm{~m} / \mathrm{s}$ the feeding amount should be uniform and the loss and breakage rate can be reduced. The feeding amount was $0.83 \mathrm{~kg}$ ears $\mathrm{s} / \mathrm{m}$, that is, $0.83 \mathrm{~kg}$ of maize ear was distributed on the surface of the rotor per meter per second. The authors concluded that the rear clearance between the cylinder and the concave should be $10 \mathrm{~mm}$ less than the average diameter of the ear, and their test clearance setting was $32 \mathrm{~mm}$; they also considered that the rear clearance should be equal to the ear cob diameter, and their test clearance setting was $23 \mathrm{~mm}$. The results suggested that if the grain moisture content is $37 \%$ and the cylinder rotational speed is $10 \mathrm{~m} / \mathrm{s}$, the back clearance should be smaller to reduce the loss.

Furthermore, the loss of kernels passing through the cleaning screen was usually low, generally $25.08 \mathrm{~kg} / \mathrm{hm}^{2}$ with a median of $12.54 \mathrm{~kg} / \mathrm{hm}^{2[62]}$. The highest separation loss was up to $188.1 \mathrm{~kg} / \mathrm{hm}^{2}$, which was mainly caused by the blockage of the separation screen, especially when the grain moisture content was higher than $25 \%$, the separation loss increased rapidly. It was also shown that reducing the feeding amount can effectively reduce separation loss. Additionally, it was found that the improper adjustment of the sieve hole and fan will cause kernels to fall to the ground after passing through the sieve, thereby causing losses; if the air volume is too large the grains will be blown out directly, while if the sieve hole is too small the grains will be discharged from the sieve box if they cannot pass through the sieve hole.

Morvaridi et al. ${ }^{[65]}$ found that the traveling speed of the harvester did not have a significant impact on the header loss, however also showed that the drum speed had a significant impact on the threshing loss. The highest loss rate $(5 \%)$ was observed at processing traveling speed of $2.23 \mathrm{~km} / \mathrm{h}$ and a drum speed of 550 $\mathrm{r} / \mathrm{min}$. Moreover, Miu et al. ${ }^{[66]}$ showed that, when the rotating speed of the cylinder was low, the threshing loss was increased due to imperfect threshing; however, when the moisture content of the fed material other than grain (MOG) was high, the loss from cleaning was increased due to the increase of friction between the 
MOG and grains. Additionally, it was found that with increasing feeding amount the threshing loss decreased but the separation loss increased. Furthermore, the research of Miu et al. ${ }^{[66,67]}$ on wheat mechanical harvesting also showed that the main variable controlling the harvest loss is the feeding speed of MOG. With increasing MOG feeding speed, the grain loss increased exponentially, however low feeding speed caused high grain damage. Under a given yield level, the feeding speed of MOG was directly proportional to the moving speed. Therefore, at high yield, harvesting at a lower forward speed can obtain a lower rate of grain damage and low harvest loss.

\subsection{Effects of harvester operation on harvest loss}

Before field operation, the operating speed, header height, ear plate gap, cylinder rotational speed, concave clearance, and other parameters of the harvester should be adjusted according to the type of harvester, maize variety, planting density, unit yield level, grain moisture, and lodging status. It has been reported that trained operators can control the separation loss rate at $0.4 \%$ and the header loss rate at $1.8 \%{ }^{[23]}$. Additionally, tests have shown that during harvesting, if the header divider deviates from the maize plant row width by $10.16-12.70 \mathrm{~cm}$, the loss of falling ears caused by gathering the ear through the header will reach $156.75 \mathrm{~kg} / \mathrm{hm}^{2}$ and that if the header encounters lodging (e.g., caused by bad weather, diseases, or pests) the loss will exceed $630 \mathrm{~kg} / \mathrm{hm}^{2[46]}$. Furthermore, Ayres et al ${ }^{[8]}$ investigated the operation of 84 combine harvesters in central and northern Iowa, and found that when the row spacing of the header differed from the planting row spacing by $5 \mathrm{~cm}$ the harvest loss increased by $82 \mathrm{~kg} / \mathrm{hm}^{2}$. The header loss was found to account for $65 \%$ of the total harvest loss, and the total loss was found to have little relation with the forward speed of harvesting; however, it was shown that when the forward speed was over $4.8 \mathrm{~km} / \mathrm{h}$ the loss of falling ear increased and the loss of falling grain decreased. Paulsen et al. ${ }^{[27]}$ investigated 11 combine harvesters in Brazil, and found that the harvest loss was $36.2-320.6 \mathrm{~kg} / \mathrm{hm}^{2}$ with an average of $83.4 \mathrm{~kg} / \mathrm{hm}^{2}$ ( $1.3 \%$ of the yield). Taking harvester C8 (John Deere 9770 STS) as an example, the total harvest loss was $116.2 \mathrm{~kg} / \mathrm{hm}^{2}(1.6 \%$ of the yield), which can be considered reasonable, however, the separation loss was $92.9 \mathrm{~kg} / \mathrm{hm}^{2}$, which was the highest among all harvesters. Therefore, if the operator pays more attention to the changes in harvest loss caused by differences in the operation of the harvester and reduces the forward speed of harvesting, separation loss can be reduced. Moreover, in a study of three harvesters, Ayres et al. ${ }^{[8]}$ found that the ear loss from the header ranged from $141.08 \mathrm{~kg} / \mathrm{hm}^{2}$ to $3009.6 \mathrm{~kg} / \mathrm{hm}^{2}$ with an average of $1404.48 \mathrm{~kg} / \mathrm{hm}^{2}$. Additionally, they found that the header loss was due at least in part to the following reasons: (1) the working height of the header was relatively high. (This was done so that stones in the field would not enter the cylinder through the header during harvesting; (2) there was only one set of stem collection chains in each row of the header, which caused the stems to be pulled off and then tilted forward, resulting in the falling of ears; (3) maladjustment of the relationship between the stem pulling roller, ear plucking plate, and ear collecting chain; and (4) header shaking occurred in the wider header whic6h led to ear falling. Additionally, field observations made by our team showed that if the forward speed of the harvester increases then (1) the feeding amount will increase correspondingly and (2) the amount of separation and cleaning loss after threshing will also increase correspondingly, which leads to the increase of the weight of kernels carried by cobs and husk leaves due to imperfect separation.
Therefore, the optimal forward speed of the harvester is the speed corresponding to the minimum loss rate of threshing, separation, and cleaning in the harvester processing which can be tolerated under the amount of feed. Generally, the forward speed is determined based on field experience during maize harvesting, a trial harvest over a distance of $30-50 \mathrm{~m}$, and harvest parameters are subsequently adjusted according to the grain falling rate, ear falling rate, grain broken rate, and grain impurity rate in the field.

\section{Discussion and suggestions}

\subsection{Harvest loss is an important problem that affects the quality of maize harvest and the promotion of mechanical harvesting in China}

The yield loss of maize in the process of mechanical harvesting directly affects the harvest yield. Additionally, maize kernels falling into the field can become voluntary seedlings, which also has a significant negative effect on the growth and yield of the next season's crop. Harvest loss is a common problem in the mechanical harvesting of maize around the world. In 2012-2019, our team obtained 2987 groups of grain quality data from mechanically harvested maize in major maize production areas in China. The average harvest loss was found to be $345.2 \mathrm{~kg} / \mathrm{hm}^{2}$, equal to $3.5 \%$ of the average yield. Although the average total harvest loss did not exceed the Chinese national standard of $\leq 5 \%$, it was higher than the standard of $\leq 3 \%$ which is used in the United States, Brazil, and other countries. Furthermore, there was a large difference in harvest loss among plots, with the loss ranging from 0 to $9288.5 \mathrm{~kg} / \mathrm{hm}^{2}(0 \%-58.6 \%$ of the yield) with a coefficient of variation of $183.5 \%$, which was the most variable among all harvest quality indexes. This shows that there was a large difference between the loss of falling ears and the loss of falling kernels in different fields. This suggests that loss from mechanical harvesting is an important problem that affects the quality of maize grain harvesting in China. This seriously restricts the adoption of mechanical harvesting technology by farmers. Although the loss from falling grains and ears cannot be completely avoided in the mechanical harvesting of maize, future studies should investigate how to reduce these to the lowest level possible in China and abroad.

\subsection{Harvest loss of maize from combine harvesting mainly comes from the loss of falling ears}

The main measure that can be taken to reduce harvest loss is to control the pre-harvest loss caused by stalk lodging. The harvest loss of maize during mechanical harvesting includes ear loss and kernel loss. For the 2987 groups of grain quality data from mechanically harvested maize obtained by our team (see Section 5.1 ), the average kernel loss was $113.6 \mathrm{~kg} / \mathrm{hm}^{2}$ and the average ear loss was $351.15 \mathrm{~kg} / \mathrm{hm}^{2}$ (range: $0-8960.1 \mathrm{~kg} / \mathrm{hm}^{2}$ ), with the kernel loss accounting for $23.5 \%$ of the total average harvest loss and the ear loss accounting for $76.5 \%$. The ear loss mainly comes from the pre-harvest loss caused by ear dropping, damage from maize borer, stalk lodging during harvest, and the ear dropping loss and kernel falling loss during combine harvesting, among which the pre-harvest loss caused by stalk lodging is the main component Therefore, in the future, it is necessary to strengthen the breeding of varieties that are resistant to lodging, especially during the field drying period after physiological maturity. Furthermore, maize varieties should be matched to the local light and heat conditions, varieties suitable for mechanical grain harvesting and with resistance to lodging, maize borer, and stalk rot should be selected, and farmers should apply suitable planting densities and the 
scientific management of irrigation and fertilization; additionally, the damage from maize borer and stem rot should be prevented and controlled, the optimum harvest time should be chosen, and ear loss should be reduced. Delaying harvest can reduce the grain moisture content and thus decrease the cost of artificial grain drying. However, delaying harvest also increases the harvest loss due to stalk lodging and ear falling. Therefore, the appropriate harvest period should be chosen to achieve a balance between harvest loss and drying cost.

6.3 Development and selection of advanced maize combine harvesters, the matching of agricultural machinery with agronomy, and the training of maize producers and machinery operators will help to reduce harvest loss

A large number of studies in China and abroad have shown that harvest loss results from the interaction between many factors, including crop production practices, maize growth status, combine harvester properties, the maintenance, adjustment, and operation of combine harvesters, and environmental conditions ${ }^{[21]}$. Different types of the combine harvester, and even different machines of the same type, can have different harvest losses, due to factors such as the type of mechanical device, the working principles, the header operation, the rotational speed of the threshing cylinder, the concave clearance, the screen clearance, the rotational speed and air volume of the cleaning fan, and the personnel operation; however, among these factors, the harvest loss is mainly affected by the ear dropping from the header. The harvest loss can be effectively reduced by adjusting the operating parameters of the combine harvester before harvesting according to the specific conditions, including harvester type ${ }^{[25]}$, maize variety ${ }^{[17,18,22,24]}$, planting density and plant row spacing ${ }^{[9,15,18,19]}$, pests and disease $\mathrm{e}^{[17,18,22]}$, grain yield, grain moisture content, stalk lodging rate, weather conditions during harvest ${ }^{[20,21]}$, the terrain conditions of the maize field ${ }^{[17]}$, and so on. Therefore, the development and selection of advanced harvesting machinery and strengthening the training of maize growers and harvester operators have great potential for reducing harvest loss.

6.4 Continuously formulating and improving the technical standards and methods of maize combine harvesting and promoting the development of the standardization of maize grain harvesting technology

In order to develop maize grain mechanical harvesting technology, it is necessary to formulate and revise the appropriate technical standards and methods according to social and economic conditions and industrial development needs. These standards include the standards of the selection of maize varieties that are suitable for the combine harvesting of grain, standards for production and planting technology, harvester operation, harvest quality evaluation, etc. Formulating these standards can help establish a monitoring system for the quality of maize grain harvesting, assist in the production of harvest quality reports, and provide technical support for the promotion of maize mechanical grain harvesting technology and the reduction of harvest loss. In major maize-producing countries such as the United States, Brazil, and Argentina, the standard of maize harvest loss is no more than $3 \%$ of the yield. However, in China, the current national standard of "technical conditions for maize harvesting machinery" (GBT-21962-2008) ${ }^{[31]}$ stipulates that the maize harvest loss should be no more than $5 \%$ of the yield. As mechanized harvesting technology matures in China, the standard of harvest loss can be improved by referring to foreign harvest loss standards. Additionally, future studies should focus on ways to quantify the "invisible loss" from grains that are broken or pulverized, and which consequently cannot be accounted for when estimating loss.

\section{Acknowledgements}

This work was supported by the National Key Research and Development Program of China (Grant No. 2016YFD0300101; No. 2016YFD03001010); the National Natural Science Foundation of China (Grant No. 31371575); the China Agriculture Research System (CARS-02-25); the Agricultural Science and Technology Innovation Project of the Chinese Academy of Agricultural Sciences.

\section{[References]}

[1] Li S K, Zhao J R, Dong S T, Zhao M, Li C H, Cui Y H, et al. Advances and prospects of maize cultivation in China. Sci Agric Sin, 2017; 50(11): 1941-1959. (in Chinese)

[2] Li L L, Xue J, Xie R Z, Wang K R, Hou P, Zhang F L, et al. Effects of grain moisture content on mechanical grain harvesting quality of summer corn. Acta Agron Sin, 2018; 44(12): 1747-1754. (in Chinese)

[3] Gao W, Chen Z, Huang Y X, Yang M L. Analysis of influencing factors on farmers' adoption of maize mechanized harvesting in Jilin Province. Transaction of the CSAM, 2012; 43(S1): 175-179, 168. (in Chinese)

[4] Pan W G, Gong Z L, Lu H Y. Factors analysis on producers' application of mechanized maize harvesting: based on empirical research of Shandong Province. China Agric Sci Bull, 2014; 30(14): 165-172. (in Chinese)

[5] Guo Y Q, Chai Z W, Wang K R, Xie R Z, Tang Q X, Liu G Z, et al. Corn harvest methods and benefit analysis. J Agric, 2017; 7(12): 8-11. (in Chinese)

[6] Hilbert J H. Machine and machine operator characteristics associated with corn harvest kernel damage. PhD dissertation. Ames: Iowa State University, 1972; 142p.

[7] Waelti H, Buchele W F, Farrell M. Progress report on losses associated with corn harvesting in Iowa. J Agric Eng Res, 1969; 14(2): 134-138.

[8] Ayres G E, Babcock C E, Hull D O. Corn combine field performance in Iowa. In: Grain Damage Symposium, Columbus: The Ohio State University, 1972; pp.1-17.

[9] David J W, Rossman E C. Mechanical harvest of corn at different plant populations. Agron J, 1956; 48(9): 394-397.

[10] Byg D M, Hall G E. Corn losses and kernel damage in field shelling. Trans ASAE, 1968; 11(2): 164-166.

[11] Mahmoud A R, Buchele W F. Distribution of shelled corn throughput and mechanical damage in a combine cylinder. Transactions of the ASAE, 1975; 18(3): 448-452.

[12] Nolte B H, Byg D M, Gill W E. Timely field operations for corn and soybeans in Ohio. Bull. Ohio Coop. Ext. Serv., Columbus, 1976; 605p.

[13] Allen R R, Musick J T, Hollingsworth L D. Topping corn and delaying harvest for field drying. Trans ASAE, 1982; 25: 1529-1532.

[14] Gleim J A, Holmes R G, Wood R K. Corn and soybean harvesting losses. American Society of Agricultural Engineers, 1990. Paper No. 90-1563; ISSN: 0149-9890.

[15] Hanna H M. Machine losses from conventional versus narrow row corn harvest. Appl Eng Agric, 2002; 18(4): 405-409.

[16] Haun W. Harvest aids for corn and soybeans. Corn Newsletter, 2009 33: 282205 . doi: 10.22004/ag.econ.282205.

[17] Klenke J R, Russell W A, Guthrie W D. Grain yield reduction caused by second generation European corn borer in BS9 corn synthetic. Crop Sci, 1986; 26(5): 859-863.

[18] Stanger T F, Lauer J G. Corn stalk response to plant population and the Bt-European corn Borer trait. Agron J, 2007; 99: 657-664.

[19] Zhang D, Liu J, Chui T, Li Y L. Effects of different row space on corn yield and machinery harvesting losses. ASABE Annual international meeting. Grand sierra resort and casino reno, Nevada, 2009; 096178. doi: 10.13031/2013.27074.

[20] Piggott S. Simulation of corn in field drydown. Master dissertation. East Lansing: Biosystems Engineering, Michigan State University, 2010; $59 \mathrm{p}$

[21] Thomison P R, Mullen R W, Lipps P E, Doerge T, Geyer A B. Corn response to harvest date as affected by plant population and hybrid. Agron J, 2011; 103(6): 1765-1772.

[22] Mahoney K J, Klapwyk J H, Stewart G A, Scott Jay W, Hooker D C. 
Agronomic management strategies to reduce the yield loss associated with spring harvested corn in Ontario. American J Plant Sci, 2015; 6(2): 372-384.

[23] Paulsen M R, Kalita P K, Rausch K D. Postharvest losses due to harvesting operations in developing countries: A review. In: American Society of Agricultural and Biological Engineers Annual International Meeting, 2015; 152176663. doi: 10.13031/aim.20152176663.

[24] Wang L, Feng G, Li Y Y, Jing X Q, Huang C L. Relationship between maize lodging resistance and agronomic traits, plant diseases, and insect pests. Crops, 2016; 2: 83-88. (in Chinese)

[25] Fu J, Chen Z, Han L, Ren L. Review of grain threshing theory and technology. Int J Agric \& Biol Eng, 2018; 11(3): 12-19.

[26] Sumner P E, Williams E J. Measuring field losses from grain combines. The University of Georgia Cooperation Extension, 2012; Bulletin 973.

[27] Paulsen M R, Pinto F A C, Jr D G S, Zandonadi R, Ruffato S, Costa A, et al. Measurement of combine losses for corn and soybeans in Brazil. In: American Society of Agricultural and Biological Engineers Annual International Meeting, 2013; 30(6): 131570965. doi: 10.13031/ aim.20131570965.

[28] Chai Z W, Wang K R, Guo Y Q, Xie R Z, Li L L, Ming B, et al. Current status of corn mechanical grain harvesting and its relationship with grain moisture content. Sci Agric Sin, 2017; 50(11): 2036-2043. (in Chinese)

[29] Guo Y, Zhang P, Li X F, Zhu J F. Study on yield loss of maize during harvesting in China - based on the surveys in 5 counties of 5 provinces. J Maize Sci, 2018; 26(5): 130-136. (in Chinese)

[30] Wiersma J, Allrich T. Grain harvest losses. 2005; Available: http://www.smallgrains.org/Techfile/Sept78.htm. Accessed on [2005-09-25].

[31] General administration of quality supervision and quarantine of the People's Republic of China and China National Standardization Administration. Technical conditions of corn harvesting machinery: GB/T 21962-2008.

[32] Johnson W H, Lamp B J, Henry J E, Hall G E. Corn harvesting performance at various dates. Transactions of the ASAE, 1963; 6(3): 268-272.

[33] Paulsen M, Pinto F, de Sena Jr D G, Zandonadi R, Ruffato S, Costa A, et al. Measurement of combine losses for corn and soybeans in Brazil. Appl Eng Agric, 2014; 30(6): 841-855.

[34] Li S K. Factors affecting the quality of maize grain mechanical harvest and the development trend of grain harvest technology. J Shihezi Univ (Nat Sci), 2017; 35(3): 265-272. (in Chinese)

[35] Shay C W, Ellis L V, Hires W G. Measuring and reducing corn harvesting losses. Agricultural Guide: University of Missouri Columbia Extension Division, 1983; 1280p.

[36] Minyo R, Geyer A, Thomison P, Bishop B, Lohnes D G. Ohio corn performance trials. Dep. of Horticulture and Crop Sci. Ser. 2015. Columbus: Ohio State Univ. OSUE/OARDC. Available: http://hostedweb.cfaes.ohio-state.edu/perf/archive.htm. Accessed on [2015-02-13]

[37] Parvej M R, Hurburgh C R, Hanna H M, Licht M A. Dynamics of corn dry matter content and grain quality after physiological maturity. Agron J, 2020; 112(2): 998-1011.

[38] Kutzbach H D, Quick G R. Harvesters and threshers: Grain. In: Stout B A, Cheze B. (Ed.) CIGR Handbook of Agricultural Engineering, Volume III: Plant Production Engineering. St. Joseph: ASAE, 1999; pp.311-347.

[39] Anderson B, White D. Evaluation of methods for identification of corn genotypes with stalk rot and lodging resistance. Plant Dis, 1994; 78(6): 590-593

[40] Quesadaocampo L M, Alhaddad J, Scruggs A C, Buell CR, Trail F. Susceptibility of maize to stalk rot caused by Fusarium graminearum deoxynivalenol and zearalenone mutants. Phytopathology, 2016; 106(8): 920-927.

[41] Yu C, Saravanakumar K, Xia H, Gao J, Fu K, Sun J, et al. Occurrence and virulence of Fusarium spp. associated with stalk rot of maize in North-East China. Physiol Mol Plant P, 2017; 98: 1-8.

[42] Mueller D S, Sisson A J, Robertson A E. Corn yield loss estimates due to diseases in the United States and Ontario, Canada from 2012 to 2015.
Plant Health Prog, 2016; 17(3): 211-222.

[43] Shauck T C, Smeda R J. Factors influencing corn harvest losses in Missouri. Crop Management, 2011; 10(1). doi: 10.1094/CM-2011-0926-01-RS.

[44] Monsanto. Considering corn harvest losses and drying costs. Agronomic Spotlight, 2010; pp. 1-2.

[45] Brandon H. Harvest efficiency boosts quality of stored corn. Southeast Farm Press, 2009. Available: https://www.farmprogress.com/grains/ harvest-efficiency-boosts-quality-stored-corn. Accessed on [2009-08-27].

[46] Md Rasel Parvej, Charles R. Hurburgh, H. Mark Hanna, Mark A. Licht. Dynamics of corn dry matter content and grain quality after physiological maturity. Agronomy Journal, 2020; 112(2): 998-1011.

[47] Nielsen R I. Field dry down of mature corn grain. Purdue University, Corn News Network, 2011. Available: http://www.kingcorn.org/news/ timeless/GrainDrying.html. Accessed on [2011-09-09]

[48] Erickson B, Valentin L. Evaluating corn harvest timing. Top Farmer Crop Workshop Newsletter, 2008; pp. 1-3.

[49] University of Arkansas, United States Department of Agriculture, and County Governments Cooperating. Cron production handbook. MP437-250-6-08R, Gary Huitink, 8-Corn Harvesting, pp.65-72

[50] Bruns H A, Abbas H K. Effects of harvest date on maize in the humid subtropical mid-south USA. Maydica, 2004; 49(1): 1-7.

[51] ASAE D497.5 FEB2006. Agricultural machinery management data. St. Joseph, MI: ASABE, 2006; pp. 349-357

[52] Paulsen M R, Hill L D. Quality attributes of argentine corn. Appl Eng Agric, 1985; 1(1): 42-46.

[53] Xue J, Li L L, Xie R Z, Wang K R, Hou P, Ming B, et al. Effect of lodging on corn grain losing and harvest efficiency in mechanical grain harvest. Acta Agron Sin, 2018; 44(12): 1774-1781. (in Chinese)

[54] Lauer J. Some pros and cons of letting corn stand in the field through winter. Wisconsin Crop Manager, 2004; 11(26): 170-171.

[55] Paulsen M R, Nave W R. Corn damage from conventional and rotary combine. Trans ASAE, 1980; 23(5): 1110-1116.

[56] Thomas R, Bingen T R. Trends in the process technology of grain crop harvesting. Agritechnica, 2003; 58: 362-363.

[57] Lien R M, Haugh C G, Silver M J, Ashman R B. Machine losses in field harvesting popcorn. Transactions of the ASAE, 1976; 19(5): 827-829.

[58] Pishgar-Komleh S, Keyhani A, Mostofi M R, Jafari A. Assessment and determination of seed-maize combine harvesting losses and energy consumption. Elixir Agric, 2013; 54: 12631-12637.

[59] Srison W, Chuan-Udom S, Saengprachatanarak K. Design factors affecting losses and power consumption of an axial flow corn shelling unit. Agric Nat Resour, 2016; 38(5): 421-425.

[60] Chuan-udom S, Chinsuwan W. Threshing unit losses prediction for Thai axial flow rice combine harvester. Ama Agr Mech Asia Af, 2015; 40(1): 50-54.

[61] Chuan-udom S. Operating factors of Thai threshers affecting corn shelling losses. Songklanakarin J Sci Technol, 2013; 35(1): 63-67.

[62] Monsanto. Understanding harvest losses in corn and soybean. Agronomy Advice, 2015; pp.1-10.

[63] SteponaviČius D, PuŽauskas E, Špokas L, Jotautiene E, Kemzurait A, PetkeviČius S. Concave design for high-moisture corn ear threshing. Mechanika, 2018; 24(1): 80-91

[64] Pekkevicius S, Spokas L, Steponavicius D. Substantiation of technological parameters of wet maize threshing. Agron Res, 2008; 6(Special issue): 271-280.

[65] Morvaridi N, Asoodar M A, Khademalhosseini N A. Evaluation of losses on corn (Zea Mays) combine harvester as effected by operational conditions under Khouzistan climate condition. In: The 10th International Congress on Mechanization and Energy in Agriculture, Antalya, Turkiye, 2008; pp.293-298.

[66] Miu P I, Beck F, Kutzbach H-D. Mathematical modelling of threshing and separating process in axial threshing units. 1997; ASAE Paper No. 971063.

[67] Miu P I. Mathematical modelling of material other-than-grain separation in threshing units. 1999; ASAE Paper No:993208. 